\title{
Active Rheumatoid Arthritis in Central Africa: A Comparative Study Between Sudan and Sweden
}

\author{
Amir I. Elshafie, Abdalla D. Elkhalifa, Sahwa Elbagir, Mawahib I.E. Aledrissy, \\ Elnour M. Elagib, Musa A.M. Nur, Tomas Weitoft, and Johan Rönnelid
}

ABSTRACT. Objective. To compare clinical characteristics and treatment between simultaneously investigated Sudanese and Swedish outpatients with rheumatoid arthritis (RA).

Methods. Outpatients with RA from Sudan $(n=281)$ and Sweden $(n=542)$ diagnosed according to the 1987 American College of Rheumatology criteria were recruited between December 2008 and September 2010 and compared concerning clinical presentation, treatment, and laboratory findings, including immunoglobulin $\mathrm{M}$ with rheumatoid factor (IgM-RF).

Results. Sudanese patients had lower inclusion age (median 49 vs $68 \mathrm{yrs}$ ), disease duration (48 vs $107 \mathrm{mos}$ ), and disease onset age (43 vs 56 yrs) as compared with Swedish patients ( $\mathrm{p}<0.0001$ for all). When stratified concerning the age of inclusion, Swedish patients between 41-50 years had, however, a significantly lower age of onset, with a similar trend for all age groups above 30 years. The female preponderance was higher among Sudanese patients $(89.3 \%$ vs $72.5 \%, \mathrm{p}<0.0001)$, and smoking was nonexistent among Sudanese female patients $(p<0.0001)$. Erythrocyte sedimentation rate levels and number of tender joints were significantly higher among Sudanese patients. The proportion of IgM-RF positivity was lower among Sudanese patients with RA $(52.4 \%$ vs $75.5 \%, \mathrm{p}<$ 0.0001). Higher proportions of Sudanese patients with RA were treated with methotrexate (MTX) and disease-modifying antirheumatic drug combinations, but none of them used biologics. Sudanese patients used lower doses of MTX and sulfasalazine $(\mathrm{p}<0.0001)$ and higher doses of prednisolone $(\mathrm{p}<0.0001)$ than Swedish patients.

Conclusion. Sudanese patients with RA have significantly higher disease activity and are often IgM-RF-seronegative. Together with reports from Uganda and Cameroon, our data indicate a cluster of highly active and often seronegative RA in central Africa. (First Release August 1 2016; J Rheumatol 2016;43:1777-86; doi:10.3899/jrheum.160303)

\section{Key Indexing Terms: RHEUMATOID ARTHRITIS RHEUMATOID FACTOR}

\section{SUDAN DISEASE SEVERITY DISEASE-MODIFYING ANTIRHEUMATIC DRUGS}

Studies on rheumatoid arthritis (RA) in Africa are encumbered with logistic challenges. Many countries on the continent are also currently undergoing economic transformations, urbanization, and acquisition of Western lifestyles, all factors that might change both the clinical presentation and prevalence of RA. Studies from different parts of Africa have reported varying RA disease severity $1,2,3,4,5,6,7$. Two old reports from Zimbabwe and Nigeria described the disease being less severe in Africa when compared with white patients with $\mathrm{RA}^{8,9}$. In central and western Africa, the disease severity has been

From the Department of Immunology, Genetics and Pathology, Uppsala University, Uppsala; Rheumatology Unit, Gävle Hospital, Gävle; Section of Rheumatology, Center for Research and Development, Uppsala University, Region of Gävleborg, Sweden; Khartoum Fertility Center; Rheumatology Unit, Alribat University Hospital, Khartoum;

Rheumatology Unit, Military Hospital, Omdurman, Sudan.

Financial support was obtained from the Swedish Research Council, the Swedish Rheumatism Association, Agnes Mac and Rudberg Foundation, King Gustav Vth 80-year Foundation, and the Signe and Reinhold Sund's Foundation for Rheumatological Research. Phadia/Thermofisher sponsored reagents for IgM-RF investigations.

A.I. Elshafie, MD, PhD, Department of Immunology, Genetics and Pathology, Uppsala University; A.D. Elkhalifa, MD, Rheumatology Unit, Gävle Hospital; S. Elbagir, MD, Department of Immunology, Genetics and reported to be relatively low ${ }^{10,11,12}$. Some reports from the eastern ${ }^{13,14}$ and southern ${ }^{1}$ parts of Africa published during the last 40 years have claimed that disease severity is increasing. Two more reports have shown divergent results: In a population-based study, Malemba, et al argued that the clinical picture of RA in Congolese patients was less severe than in Western countries and that most patients had no extraarticular manifestation or bone erosions ${ }^{2}$, whereas a study in Nigeria determined that the disease was severe and more than $29 \%$ of the patients had extraarticular manifestations ${ }^{15}$.

Pathology, Uppsala University, and Khartoum Fertility Center; M.I. Aledrissy, MD, Rheumatology Unit, Alribat University Hospital; E.M. Elagib, MD, FRCP, Rheumatology Unit, Military Hospital; M.A. Nur, MD, FRCP, Rheumatology Unit, Alribat University Hospital; T. Weitoft, MD, PhD, Rheumatology Unit, Gävle Hospital, and Section of Rheumatology, Center for Research and Development, Uppsala University; J. Rönnelid, MD, PhD, Department of Immunology, Genetics and Pathology, Uppsala University.

Address correspondence to Dr. A.I. Elshafie Hassan, Department of Immunology, Genetics and Pathology, Rudbeck Lab C5, Uppsala University Hospital, S-751 85 Uppsala, Sweden.

E-mail:amir.elshafie@igp.uи.se

Full Release Article. For details see Reprints/Permissions at jrheum.org. Accepted for publication June 16, 2016.

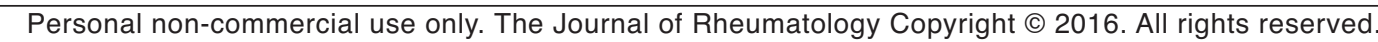


To date, the exact prevalence of RA in Africa is not well known ${ }^{1}$. One reason might be that reports from different parts of Africa have used different RA criteria for diagnosis ${ }^{16}$ and that the age structure differs considerably ${ }^{11}$. Some papers have reported the disease prevalence in Africa to be lower than that in Europe ${ }^{1,9,16}$, others claim that the prevalence is increasing ${ }^{1,5,6,15,17}$, and Kalla and Tikly postulated that this variation could be related to urbanization and the change in lifestyle in Africa ${ }^{4}$. A recent well-conducted epidemiological study from Kinshasa, the Democratic Republic of Congo, found the global prevalence of RA to be $0.6 \%$, varying from $0.07 \%$ in the $18-28$ age range to $6.25 \%$ among those aged $80-89$ years ${ }^{1}$.

To our knowledge, there are no scientific publications about the prevalence or the severity of RA in modern Sudan, only 1 paper describing the dental status of patients with unclassified RA in Khartoum from $2011^{18}$.

Although population-based studies are superior in comparing the clinical picture between 2 countries, Sudan imposes big problems because of economic and transportation issues, and the fact that rheumatology specialist care is only available in the capital Khartoum, among other things. Given the previous reports about the changing appearance of RA in Africa, we therefore decided to perform a comparative hospital-based study between all Sudanese and Swedish patients with RA attending outpatient clinics during the same time period.

\section{MATERIALS AND METHODS}

Patients. Our cross-sectional, hospital-based study was conducted in 3 different rheumatological outpatient clinics, Gävle Hospital in Sweden and Alribat University Hospital and Omdurman Military Hospital in Khartoum, Sudan. Every patient was included on the first occasion when they visited any of the outpatient clinics. The rheumatology clinic at Gävle Hospital serves as a referral center for primary healthcare and other hospital specialists in Gävleborg county, encompassing 170,000 inhabitants, and the clinical information used in our study had been stored in the nationwide online RA registry ${ }^{19}$, which is estimated to include $75 \%-80 \%$ of all patients with RA in the region. The Alribat University Hospital and the Military Hospital have the 2 biggest rheumatology outpatient units in Sudan. They serve patients related to the national police and military forces (employees and their relatives), and also provide help to unrelated civilian Sudanese patients without exception. Patients can approach the rheumatology units directly or indirectly through referral. Patients who cannot afford payment for the outpatient visit are also seen by the rheumatologist on equal terms. A maximum of $10 \%$ of all Sudanese patients with RA are estimated to be treated either in the private sector (evening services by the 4 rheumatologists in Sudan) or abroad; these patients generally have a better economic situation and are not included in our study. It is the impression of the Sudanese rheumatologists (MIEA, EME, and MAMN) that except for these external patients, there is no selection bias according to social background or financial circumstances. The coverage was good, with only $2 \%$ of the outpatients attending the Sudanese clinics for the first time during the inclusion period not wanting to participate. Our estimation was that these 2 units received $75 \%-85 \%$ of all Sudanese patients with RA attending rheumatologists in Sudan, and that the female:male ratio among the included patients represented the true ratio in Sudan. For the Sudanese patients, there are no centrally stored patient records, instead the individual record is kept by the patient and presented to the rheumatologist at admission. Clinical infor- mation from all patients and blood samples from the Sudanese patients were obtained during outpatient visits between the first of December 2008 and the end of September 2010, and was recorded by 2 of the coauthors (AIE and SE) under the supervision of 3 rheumatology specialists (MIEA, EME, and MAMN). Data on disease onset and evaluation of radiological investigations were retrieved from the written patient records, which were brought by the patients themselves. None of the Sudanese patients had fever or any other general signs of infection at the time of inclusion.

These 3 rheumatologists represent $75 \%$ (3/4) of the known specialists working in Sudan during the time of patient inclusion. According to a 2008 census, the former Republic of Sudan had 39 million inhabitants at that time.

RA diagnosis was established by rheumatology specialists according to the 1987 American College of Rheumatology criteria ${ }^{20}$. A total of 281 consecutive Sudanese patients with RA were included in our study. Serum was separated by centrifugation and frozen on dry ice within $2 \mathrm{~h}$ of sampling, stored at $-70^{\circ} \mathrm{C}$, and transported frozen on dry ice to Uppsala. Approval of the Sudanese studies was obtained from the Ethical Committees of Alribat University Hospital and Omdurman Military Hospital, and written informed consent was obtained from all patients before sampling.

The clinical data for the Swedish patients with RA had been entered by the patients themselves into the computerized national Swedish RA Quality-of-care registry and then completed by the responsible physician. At every visit, information was recorded about tender and swollen 28-joint counts, pain, and general health on visual analog scales, erythrocyte sedimentation rate (ESR), C-reactive protein, and 28-joint Disease Activity Score, in conjunction with the Health Assessment Questionnaire and the EQ-5D. Data on immunoglobulin M with rheumatoid factor (IgM-RF) and disease onset were recorded once. A total of 542 Swedish patients with RA were included during the same inclusion period as the Sudanese patients. Oral informed consent was obtained from each patient and approval to use the registry data was obtained from the regional ethical board in Uppsala.

The clinical data from the Sudanese and Swedish cohorts included age, sex, disease duration, age at symptom onset, age at time of diagnosis, number of tender joints counted from the European League Against Rheumatism 28-joint count ${ }^{21}$, smoking, IgM-RF status, ESR, smoking habits (ever smoker vs never smoker), and types and doses of treatments used. The blood hemoglobin $(\mathrm{Hb})$ level was also recorded for $176(62.6 \%)$ of the Sudanese patients, and evaluation of hand radiographs was available for $60(21.4 \%)$ of the patients. Information about hand and wrist deformities (z-deformity, swan neck deformity, and boutonniere deformity) was recorded for 252 (89.7\%) of the Sudanese patients with RA

$R F$ measurement. An enzyme immune assay (Elias, Phadia/Thermofisher) was used to measure IgM-RF in the Sudanese patients; analyses were performed in Uppsala, Sweden. Positive results were defined as $>3.9 \mathrm{IU} / \mathrm{ml}$, representing $97.6 \%$ specificity among 168 Sudanese healthy blood donors [specificity was aligned to the anticyclic citrullinated peptide 2 (CCP2) specificity in the same cohort]. For Swedish patients, IgM-RF was evaluated by latex agglutination and confirmed by nephelometry (Immage, Beckman Coulter). In a previous comparison between these 2 measures performed on 269 Swedish patients with RA, they showed a $\kappa$ coefficient of 0.73 and very similar diagnostic sensitivity: $67.3 \%$ for the Immage nephelometry and $66.5 \%$ for IgM-RF with Phadia Elia (Johan Rönnelid, unpublished data). Anti-CCP2 data were not available in the Swedish RA registry.

Statistics. The Mann-Whitney U test was used to compare differences between groups. The chi-square test was used to test for differences between proportions, and using Fisher's exact test when appropriate. P values $<0.05$ were considered significant.

\section{RESULTS}

Age and sex aspects. Among the 281 Sudanese patients with RA, 251 were women and 30 men, with a mean age of 48.3 years (SD 13.0) and a median of 49 years (range 18-80). The 542 Swedish patients with RA consisted of 393 women and

Personal non-commercial use only. The Journal of Rheumatology Copyright $\odot$ (2016. All rights reserved 
149 men with a mean age of 66.6 years (SD 12.9) and a median of 68 years (range 24-92). The number of patients with early RA (disease duration $\leq 12$ mos) from Sudan and Sweden were 81 and 71, respectively. The median age of the Sudanese patients was significantly lower than that of the Swedish patients $(\mathrm{p}<0.0001$; Figure $1 \mathrm{~A}$ and Table 1$)$; this was also true for patients with early RA investigated separately (Table 1). The percentage of women among the Sudanese patients was significantly higher than that among the Swedish patients $(89.3 \%$ vs $72.5 \%, \mathrm{p}<0.0001)$. This difference was also seen in patients with early RA (Table 1). Sudanese patients had significantly shorter disease duration

\section{A}

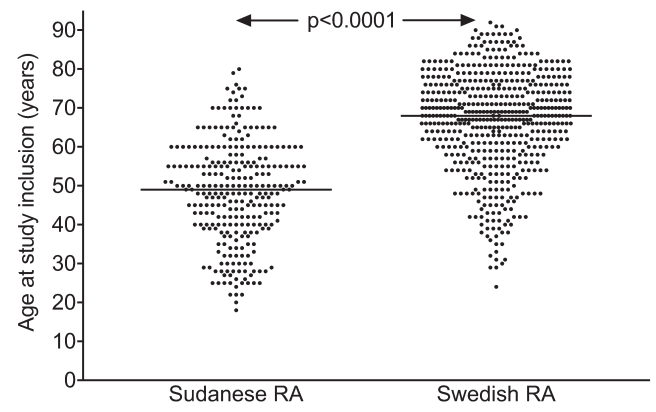

B

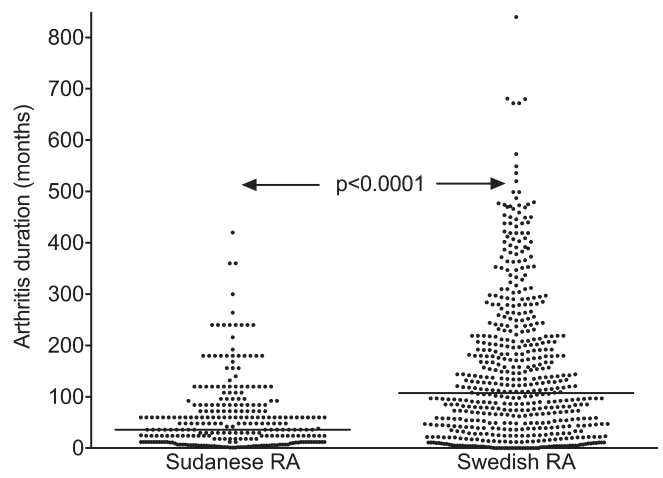

C

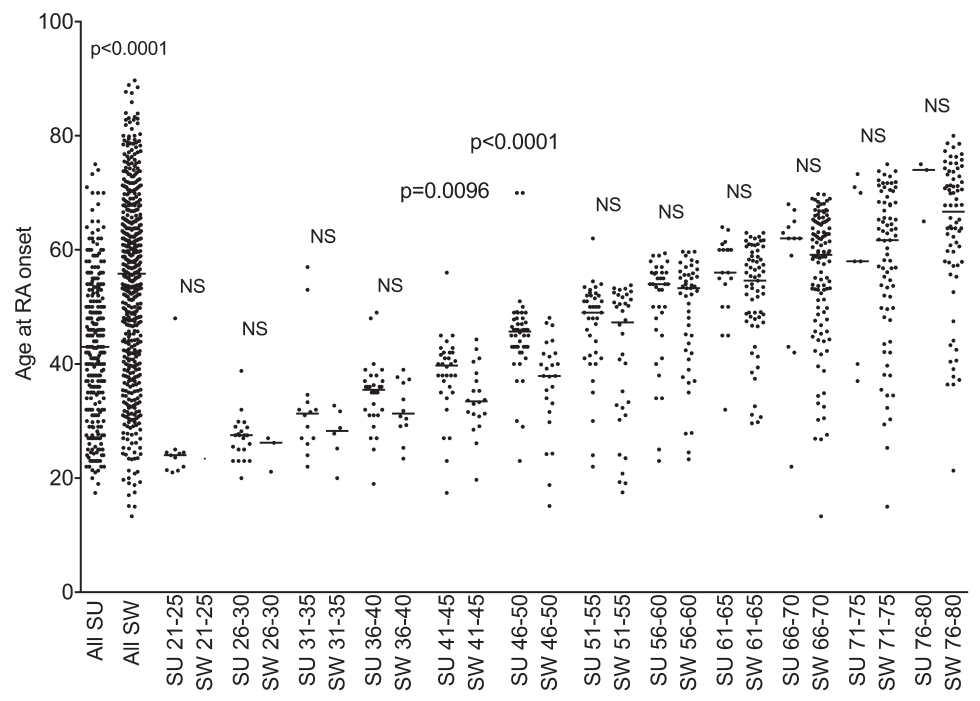

Figure 1. Temporal differences between Sudanese and Swedish patients with RA. A. Distribution of age at study inclusion. B. Distribution of disease duration at study inclusion. C. Age at RA onset, calculated by subtracting disease duration from age at study inclusion. In panel C, data for all patients are depicted to the left, and patients are thereafter stratified in 5-year groups according to age of inclusion in the study. $\mathrm{P}$ value depicts differences between median values obtained with the Mann-Whitney U test. Horizontal bars represent median levels. RA: rheumatoid arthritis; SU: Sudan; SW: Sweden; NS: not significant. 
Table 1. Clinical characteristics of patients with RA from Khartoum $(n=281)$ and Gävle $(n=542)$ at the time of study inclusion. Quantitative differences between median levels were investigated with the Mann-Whitney U test, and differences between proportions with the chi-square test or Fisher's exact test when appropriate. Individual data are missing from some of the Sudanese patients, therefore the proportional data are given as proportions of the number of patients with existing information for each variable.

\begin{tabular}{|c|c|c|c|c|}
\hline Variables & All Patients & $\mathrm{p}$ & Patients with Early RA & $\mathrm{p}$ \\
\hline Age at inclusion, yrs & $49 / 68^{*}$ & $<0.0001$ & $42 / 66^{*}$ & $<0.0001$ \\
\hline Female & $251: 281(89.3) / 393: 542(72.5)^{* *}$ & $<0.0001$ & $77: 81(95.1) / 44: 71(62.0)^{* *}$ & $<0.0001$ \\
\hline Age at onset of symptoms, yrs & $43 / 56^{*}$ & $<0.0001$ & $45 / 65^{*}$ & $<0.0001$ \\
\hline IgM-RF-positive & $131: 250(52.4) / 389: 515(75.5)^{* *}$ & $<0.0001$ & $31: 66(47.0) / 40: 64(62.5)^{* *}$ & 0.08 \\
\hline $\mathrm{ESR}, \mathrm{mm} / \mathrm{h}$ & $55 / 20^{*}$ & $<0.0001$ & $50 / 23^{*}$ & $<0.0001$ \\
\hline Patients receiving MTX only & $139: 267(52.1) / 238: 542(43.9) * *$ & 0.029 & $38: 76(50.0) / 44: 71(62.0)^{* *}$ & 0.14 \\
\hline Patients receiving DMARD combination & $56: 267(22.0) / 73: 542(13.5)^{* *}$ & 0.006 & $11: 76(14.5) / 3: 71(4.2)^{* *}$ & 0.03 \\
\hline MTX dose, patients receiving MTX only, mg/week & $\mathrm{k} \quad 12.5 / 15^{*}$ & $<0.0001$ & $10 / 15^{*}$ & $<0.0001$ \\
\hline Patients receiving PSL only & $10: 267(3.7) / 28: 542(5.2)^{* *}$ & 0.37 & $3: 76(3.9) / 1: 71(1.4)^{* *}$ & 0.34 \\
\hline PSL dose, mg/day & $5 / 5^{*}$ & $<0.0001$ & $5 / 5^{*}$ & 0.095 \\
\hline Patients receiving NSAID only & $37: 267(13.9) / 31: 542(5.7)^{* *}$ & $<0.0001$ & $14: 76(18.4) / 3: 71(4.2)^{* *}$ & 0.007 \\
\hline Patients receiving LEF only & $2: 267(0.7) / 12: 542(2.2)^{* *}$ & 0.13 & $0: 76(0 \%) / 0: 71(0 \%)^{* *}$ & - \\
\hline LEF dose, $\mathrm{mg} / \mathrm{day}$ & $10 / 10^{*}$ & 0.17 & - & - \\
\hline Patients receiving biologics & $0: 267(0) / 72: 542(13.3)^{* *}$ & $<0.0001$ & $0: 76(0) / 10: 71(14.1)^{* *}$ & 0.0007 \\
\hline
\end{tabular}

\footnotetext{
* Median value for Khartoum patients/median value for Gävle patients. ** Proportion of patients with the characteristic: all investigated patients $(\%)$ in Khartoum/proportion of patients with the characteristic: all investigated patients (\%) in Gävle. RA: rheumatoid arthritis; IgM: immunoglobulin M; RF: rheumatoid factor; ESR: erythrocyte sedimentation rate; MTX: methotrexate; DMARD: disease-modifying antirheumatic drugs; PSL: prednisolone; NSAID: nonsteroidal antiinflammatory drugs; SSZ: sulfasalazine; AZA: azathioprine; LEF: leflunomide.
}

than Swedish patients with RA (median 48 vs 107 mos, $\mathrm{p}<$ 0.0001 ; Figure $1 \mathrm{~B}$ and Table 1).

The median age at disease onset was significantly lower in the full Sudanese patient cohort when compared with all Swedish patients (43 vs 55.8 yrs, $\mathrm{p}<0.0001$; Table 1 and Figure 1C). When we divided our patients into 5-year age intervals and compared age at study inclusion, an inverse picture appeared. Sudanese patients included at ages 41-45 years and 46-50 years were significantly older than Swedish patients ( $\mathrm{p}=0.0096$ and $\mathrm{p}<0.0001$, respectively). A similar trend was found for all patients above 30 years (Figure 1C).

The median age of RA onset was 45 years for IgM-RF-positive patients, and 42 years for IgM-RF-negative patients from Sudan $(\mathrm{p}=0.03)$. The corresponding figures for Swedish patients were 58 years and 55 years $(\mathrm{p}=0.047)$. Thus, IgM-RF seropositivity was associated with a lower age of RA onset in both Sudan and Sweden (data not shown).

Disease severity. The disease severity was more pronounced among Sudanese patients when compared with Swedish patients. ESR was higher among Sudanese than among Swedish patients (median $55 \mathrm{~mm} / \mathrm{h}$ vs $20 \mathrm{~mm} / \mathrm{h}, \mathrm{p}<0.0001$; Table 1 and Figure 2A); the same difference was also evident in patients with early RA (Table 1). Sudanese patients had more tender joints than Swedish patients ( 6 vs 1 joints, $\mathrm{p}<$ 0.0001; Table 1 and Figure 2B). Significantly fewer Sudanese patients were IgM-RF-positive [131/250 (52.4\%) vs 389/515 $(75.5 \%), \mathrm{p}<0.0001$; Table 1]. In the Sudanese cohort, the median $\mathrm{Hb}$ level was $12 \mathrm{~g} / \mathrm{dl}$ among both men and women, and no difference was found between women in childbearing age ( $<50$ yrs) and elderly women (age $>50$ yrs; Figure $2 \mathrm{C}$ ). Hand examination showed that 81/252 (32.1\%) had ulnar deviation, 68/252 (27.0\%) had z-deformity, 38/252 (15.1\%) had swan neck deformity, and 25/252 (9.9\%) had boutonniere deformity. Erosions on hand radiographs were found in $56.7 \%(34 / 60)$ of the Sudanese patients with data available. No data on erosions or hand deformities were available in the RA registry for the Swedish patients.

Treatment. Comparing the full cohorts, the proportion of the Sudanese patients receiving methotrexate (MTX) and disease-modifying antirheumatic drug (DMARD) combinations was statistically higher than the proportion of Swedish patients, significantly more patients in Sudan were treated with nonsteroidal antiinflammatory drugs (NSAID) alone, and none of the biologics used in Sweden (etanercept, adalimumab, infliximab, rituximab, abatacept, and tocilizumab) were used in the Sudanese RA population (Figure 3A). The proportion of Swedes receiving antimalarial drugs was statistically higher than Sudanese (Figure 3A). The most commonly prescribed DMARD in Sudan was MTX (52.1\%), followed by sulfasalazine (SSZ; 3.7\%), azathioprine (AZA; 
A

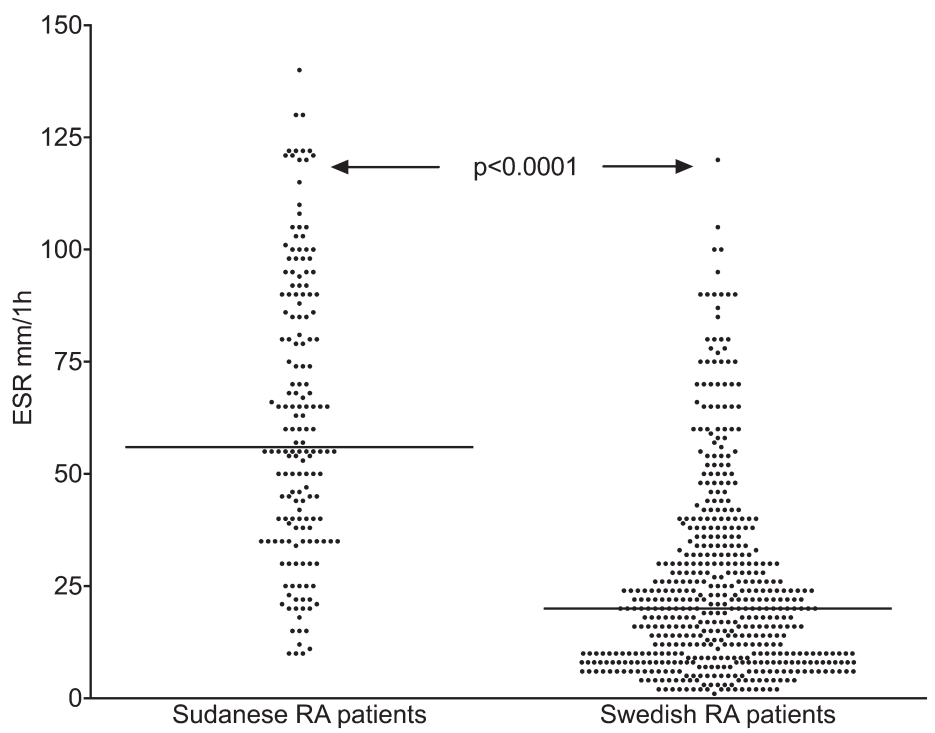

B

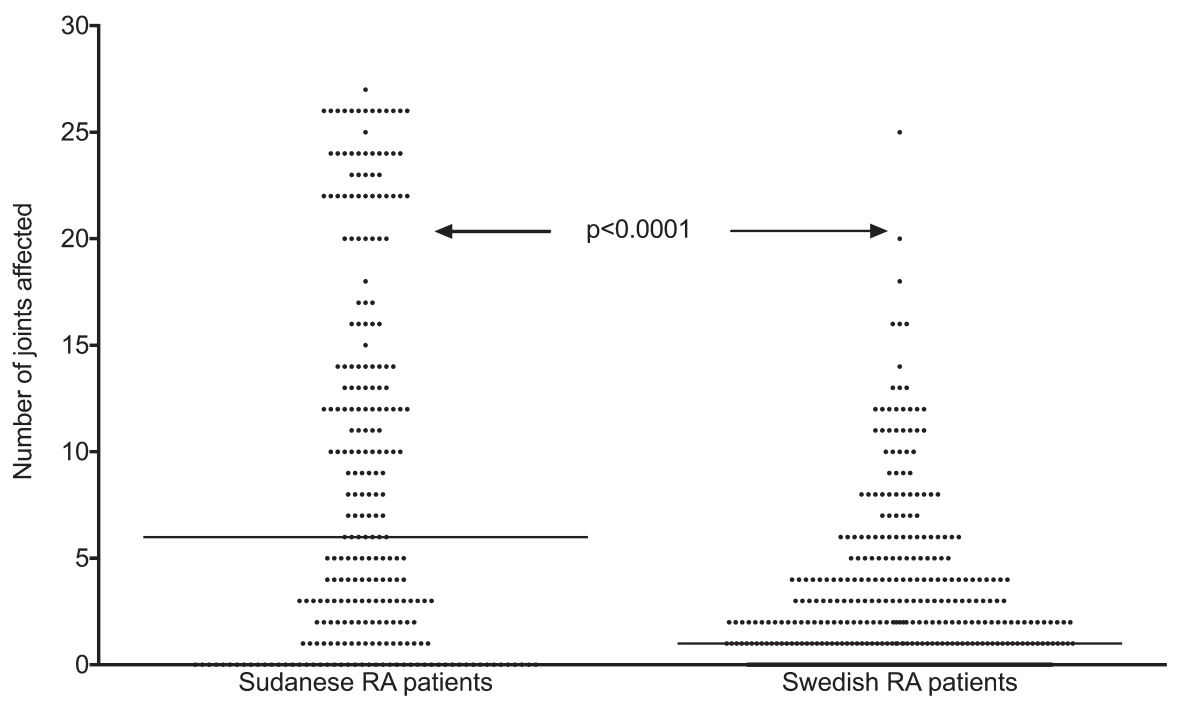

C

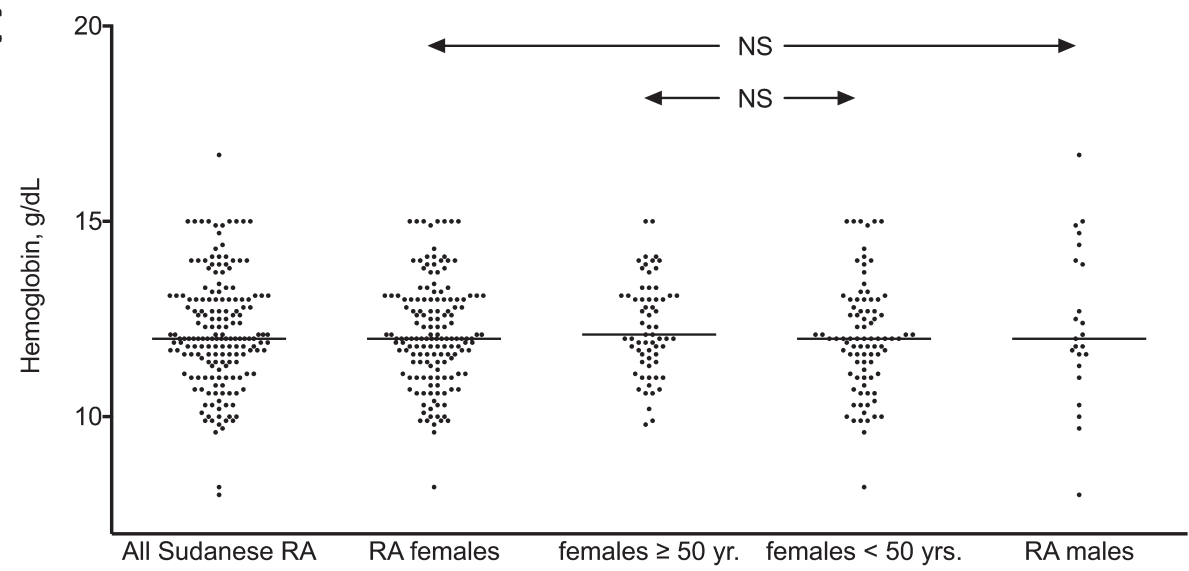

Figure 2. Measures of disease activity in Sudan and Sweden. A. ESR levels. B. No. affected joints. C. Hemoglobin levels in Sudanese patients. Lower reference ranges are represented with dotted lines (men $12.3 \mathrm{~g} / \mathrm{dl}$ and women $12.1 \mathrm{~g} / \mathrm{dl}$ ). P value depicts differences between median values obtained with the Mann-Whitney $\mathrm{U}$ test. Horizontal bars represent median levels. RA: rheumatoid arthritis; ESR: erythrocyte sedimentation rate; NS: not significant. 

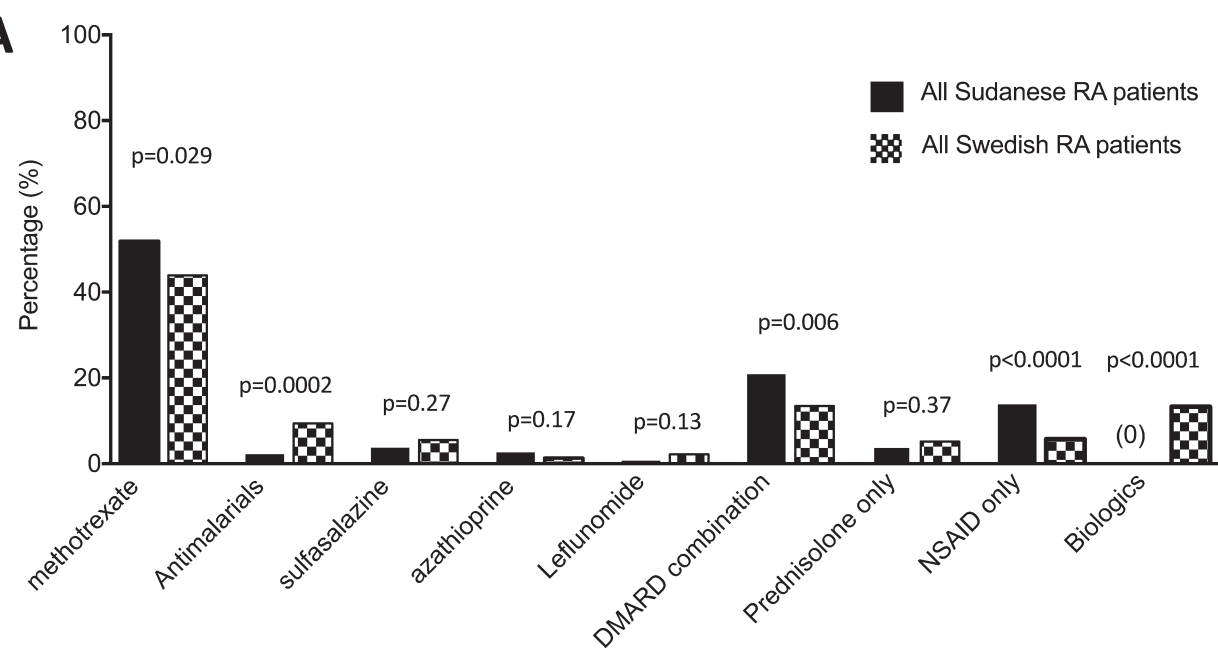

B

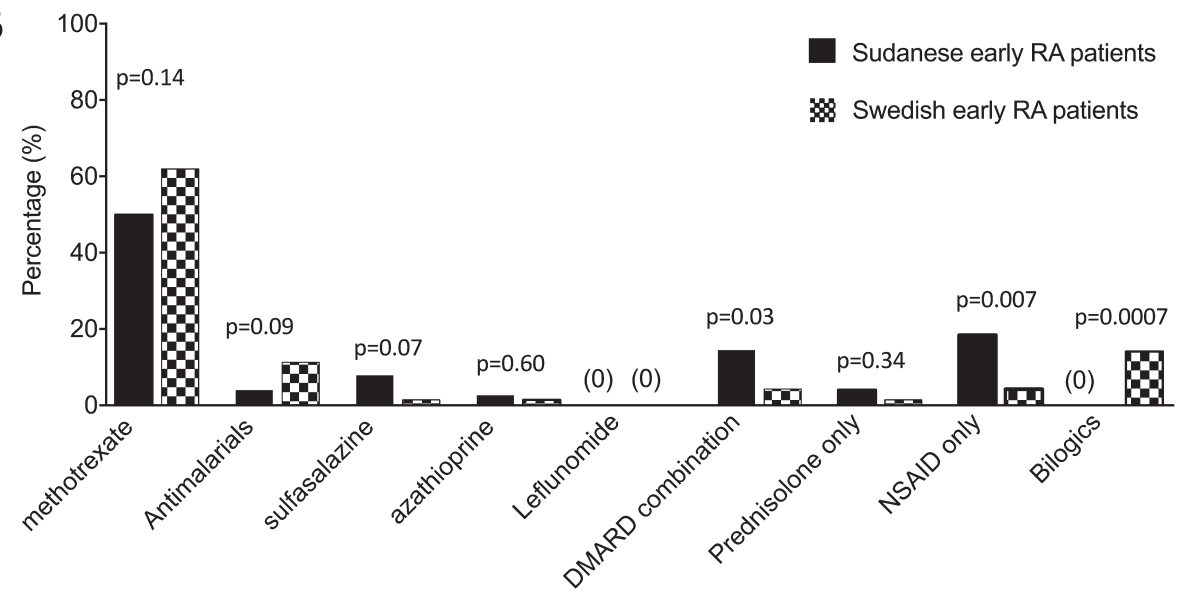

Figure 3. Comparison between Sudan and Sweden in the types and dosage of drugs used. A. Antirheumatic therapies used in all patients. B. Treatments used in patients with early RA $(<12 \operatorname{mos}$ of disease duration). RA: rheumatoid arthritis; DMARD: disease-modifying antirheumatic drugs; NSAID: nonsteroidal antiinflammatory drugs.

$2.6 \%$ ), antimalarials (2.3\%), and leflunomide (LEF; $0.8 \%)$. There was no difference in the proportion of patients using only prednisolone (PSL), SSZ, or LEF (Figure 3A). Sudanese patients used lower doses of MTX ( $p<0.0001)$, SSZ $(p<$ $0.0001)$, and AZA ( $\mathrm{p}=0.02)$ when compared with Swedish patients; doses of PSL were the same for both groups $(\mathrm{p}<$ 0.0001 ; Table 1, Figures 4A and 4F). Doses of antimalarial drugs could not be compared. Swedish patients used either hydroxychloroquine or chloroquine phosphate, while in Sudan, the patients used chloroquine phosphate only. For patients with early RA, the proportions of the Sudanese patients using DMARD combinations and NSAID only were statistically higher compared with the Swedish patients $(\mathrm{p}=$ 0.03 and $\mathrm{p}=0.007$, respectively; Figure 3B).

Environmental factors. Among the Sudanese patients with RA with data available on smoking history, $3 / 255$ (1.2\%) were ever smokers, which differed significantly $(\mathrm{p}<0.0001)$ from $63.2 \%$ (252/399) ever smokers in the Swedish RA population. All female Sudanese patients with RA were nonsmokers and $3 / 27(11.1 \%)$ of the men had a history of smoking (difference between sexes $\mathrm{p}<0.0001$ ), while there was no sex difference for Swedish patients. Similar comparisons also applied to patients with early RA investigated separately (Table 2).

\section{DISCUSSION}

The general age at RA symptom onset was significantly lower among the Sudanese than the Swedish patients. This finding agrees with another north-south comparative study between a developing and an industrialized country, showing that Canadian patients with RA also had a higher age of onset compared with patients with RA from Mexico ${ }^{22}$. We hypothesized that our finding might be secondary to the fact that Swedes have a 20-year longer life expectancy than Sudanese ${ }^{23}$. Therefore, we divided our patients into 5 -year percentiles concerning age of inclusion. Contrary to our

Personal non-commercial use only. The Journal of Rheumatology Copyright (c) 2016. All rights reserved. 

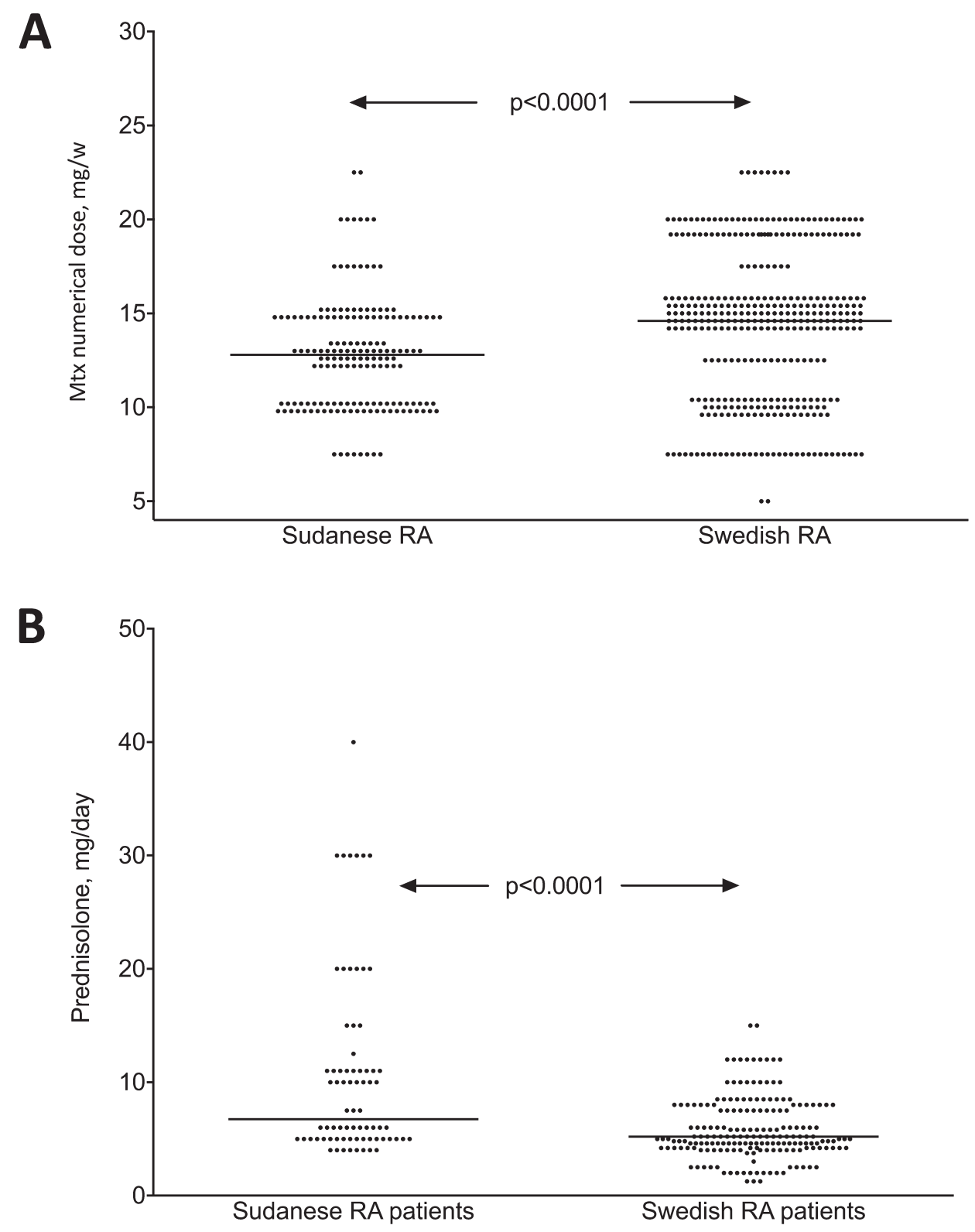

Figure 4. Doses of (A) MTX and (B) prednisolone used in the treatment of Sudanese and Swedish patients with RA. All patients receiving MTX and prednisolone are included, irrespective of any other concomitant antirheumatic therapies. P value depicts differences in median values obtained with the Mann-Whitney U test. MTX: methotrexate; RA: rheumatoid arthritis.

expectations, there was a general trend for higher age at symptom onset in Sudan for all age groups above 30 years, being significant in the 41-45-year and 46-50-year groups. One possible explanation for the higher age of RA onset among the Sudanese patients could be the higher parity among Sudanese than Swedish women ${ }^{24}$, because high parity may delay RA onset ${ }^{25,26,27}$. Another reason might be the lower percentage of IgM-RF seropositivity in Sudan, in conjunction with the significantly younger age of IgM-RF-positive patients with RA compared with
RF-negative patients in both Sudan and Sweden; this latter finding is in agreement with a previous Danish study ${ }^{28}$.

The proportion of women in the Sudanese cohort was higher than among the Swedish patients. Our Swedish RA cohort with $72.5 \%$ women is representative for the full Swedish RA population with $73 \%$ women $^{29}$, and also in agreement with other countries in the northeast of Europe: Finland (72\%), Denmark (77\%), and the Netherlands $(66 \%)^{30}$. Conversely, the higher female preponderance in Sudan is in agreement with a high female preponderance in

$$
\text { Personal non-commercial use only. The Journal of Rheumatology Copyright @ } 2016 \text {. All rights reserved. }
$$


Table 2. Comparison between smoking habits among female and male patients with RA in Sudan and Sweden. Differences between proportions were calculated with the chi-square test or Fisher's exact test when appropriate.

\begin{tabular}{|c|c|c|c|c|c|c|}
\hline \multirow[t]{2}{*}{ Variables } & \multicolumn{2}{|c|}{ All Patients } & \multicolumn{4}{|c|}{ Patients with Early RA } \\
\hline & $\begin{array}{c}\text { No. Females Smoking: } \\
\text { Total Women with } \\
\text { Smoking Data }(\%)\end{array}$ & $\begin{array}{l}\text { No. Males Smoking: } \\
\text { Total Men with } \\
\text { Smoking Data (\%) }\end{array}$ & $\mathrm{p}$ & $\begin{array}{c}\text { No. Females Smoking: } \\
\text { Total Females with } \\
\text { Smoking Data }(\%)\end{array}$ & $\begin{array}{l}\text { No. Males Smoking: } \\
\text { Total Males with } \\
\text { Smoking Data }(\%)\end{array}$ & $\mathrm{p}$ \\
\hline Ever smoker by sex, Khartoum & $0: 228(0)$ & $3: 27(11.1)$ & $<0.0001$ & $0: 66(0)$ & $2: 4(50.0)$ & $<0.0001$ \\
\hline Ever smoker by sex, Gävle & $193: 300(64.3)$ & $59: 99(59.6)$ & 0.39 & $20: 35(57.1)$ & $10: 12(83.3)$ & 0.10 \\
\hline
\end{tabular}

RA: rheumatoid arthritis.

Burkina Faso (81\%), Egypt (85\%), Cameroon (95\%), and Senegal $(91 \%)^{3,31,32,33}$. Thus, there seems to be a rather uniform finding of a higher female preponderance of RA in Africa as compared with in Europe.

Significantly fewer Sudanese patients with RA were IgM-RF-positive, agreeing with previous studies from other countries in west and central Africa: Nigeria (48\% and 13\% seropositive $)^{9,12}$, Congo $(33 \%)^{1}$, Uganda $(28 \%)^{34}$, and Zimbabwe $(37 \%)^{35}$, but differing from western Africa: Senegal (84\% in rural areas and $88 \%$ in urban areas) ${ }^{32}$ and Morocco $(78 \%)^{36}$, or from eastern Africa: Kenya (77\%) ${ }^{37}$. This discrepancy may hint that different RA subsets dominate in different parts of Africa, and that the genetic and/or environmental triggering mechanisms might differ ${ }^{38}$. The Swedish RA registry does not contain information regarding anti-CCP or anticitrullinated protein antibodies (ACPA) in general, and no comparison could be made. We believe the difference in the distribution of RF reactivity in Africa would be accompanied with the same pattern for anti-CCP, because of the close association between the occurrence of RF and anti-CCP in both our earlier Swedish ${ }^{39}$ and our present Sudanese cohort (data not included).

Except for smoking, which has consistently been related to an increased risk of $\mathrm{RA}^{38,40}$, relatively little is known about environmental factors contributing to RA development. Smoking among women is very uncommon in Sudanese society. Earlier data on cigarette smoking in Sudan ${ }^{41}$ revealed the prevalence of cigarette smoking among women to be much lower $(0.7 \%)$ than among men $(12.1 \%)$; data matching our RA cohort ( $0 \%$ and $11.1 \%$, respectively). So what could be the triggering mechanism behind RA development among Sudanese women? We hypothesize that dukhan (smoke baths $)^{42}$ practiced by Sudanese women might be a triggering factor for the development of RA in Sudan. Dukhan is a universal custom among married women in Sudan. The women sit covered by a blanket on a low footstool over a hollowing in the ground where talh wood is burned. The women will then be exposed to the smoke of the burning wood, and the inhaled smoke may reach the lungs, leading to systemic inflammation ${ }^{43}$. Dukhan is not common among Sudanese men. We have no epidemiological data about dukhan habits in our cohort or in Sudan in general, but it is practiced by almost all married Sudanese women. Thus, we hypothesize that dukhan might be another environmental RA risk factor acting through the lungs in a similar manner to cigarette smoking ${ }^{38}$, silica exposure ${ }^{44,45}$, traffic pollution ${ }^{46}$, or most recently, occupational exposure to textile dust ${ }^{47}$. The low prevalence of autoantibody-positive RA in our Sudanese cohort is, however, an argument against this hypothesis, because the strong association between smoking and RA has been reported to be confined to the ACPA-positive RA subset, at least among whites ${ }^{38}$.

The Sudanese patients with RA had higher disease activity, as reflected by higher ESR and numbers of tender joints. In comparison with what had been claimed about the disease severity of patients with RA from Africa ${ }^{1,15}$, our Sudanese patients have very active disease and high frequency of radiological erosions and hand deformities. Reports from Uganda described RA as severe, many with erosions $(70 \%)$, and $<30 \%$ of the patients with $\mathrm{IgM}-\mathrm{RF}^{34}$. Considering our results and the Ugandan data, there seems to be a clustering of highly active and often seronegative disease in central Africa. Median $\mathrm{Hb}$ levels were similar among Sudanese men and women with RA. At Alribat University Hospital, the reference range for women was 11-14 g/dl, and for men 12-16 g/dl (Professor Anwar Kurdofani and Professor Abderhman Tambal, personal communication). Using these Sudanese reference ranges that are lower than in Sweden, 16\% of our female patients with $\mathrm{RA}$ with $\mathrm{Hb}$ information were anemic.

The varieties of treatment used were similar in the 2 populations except for biologics, which were used only in Sweden. Most probably this is a cost issue. Sudanese patients have less money and must pay for their own drugs, whereas Swedish patients are part of a social welfare system that pays for all prescribed drugs over a certain limit (currently about US\$260/yr). There has also been an argument that tumor necrosis factor blockers might impose safety issues in developing countries in which the proportion of inhabitants with manifest or latent tuberculosis is high ${ }^{48}$. A higher proportion of Sudanese patients with RA used MTX alone or DMARD combinations when compared with the Swedish patients with RA. This difference, especially the increased use of DMARD combinations in Sudan, should probably be viewed in the context of the absence of biologics among the Sudanese patients because combined therapy has

Personal non-commercial use only. The Journal of Rheumatology Copyright $\subset$ $\subset$ 2016. All rights reserved 
been found to be superior than the use of MTX monotherapy alone 49,50 .

Treatment with NSAID only was significantly more common among Sudanese patients, and this was also seen for patients with early RA, investigated separately. Among the Sudanese patients, $13.9 \%$ (37/267) used only NSAID, and among the patients with early RA, the corresponding figure was $18.4 \%$. We hypothesize that the reasons might be a fear of using what might be regarded as cytotoxic drugs, inadequate access to drugs, a cost issue, or a combination of these factors. This finding is important and merits further investigation. Focused information on the importance of early and efficient treatment to patients with newly diagnosed RA might represent a very cost-effective way of decreasing disease activity and disability among Sudanese patients with RA.

Sudanese patients generally used lower doses of MTX and higher doses of PSL than Swedish patients. Increased PSL usage might be due to an intent to obtain a fast clinical response in patients with flares in a healthcare context in which regular followup is difficult.

The clinical comparison between Sudan and Sweden has obvious weaknesses. The most obvious is the patient selection - all rheumatology specialists active in Sudan at the time of inclusion were situated in Khartoum, i.e., far from many areas of the country. We are also aware that the social situation differs substantially between Sudan and Sweden, and that this probably has an effect on which patients with RA will have the possibility to approach a rheumatology outpatient clinic in the 2 countries. The included patients correctly describe patients with RA attending rheumatology specialist care during the inclusion period, because almost all patients with RA attending 3 of the 4 Sudanese rheumatologists active during the inclusion period have been participating in our study. Although there probably is a selection bias concerning which patients with RA eventually attended the outpatient clinics, the social responsibility that is associated with the Sudanese family structure together with the Sudanese charity system will help patients in need to see a rheumatologist. Thereafter, the compliance to prescribed treatment is probably a bigger problem, both economically (because MTX is less affordable than, for example, antiparasite drugs) as well as logistically, because many patients live far from pharmacies, which have irregular supplies of drugs.

Data on $\mathrm{Hb}$ and radiographs were available only from a fraction of the patients, and there is an obvious risk that patients for whom these investigations had been ordered represented a subgroup with highly active disease and/or patients who could afford these investigations. Also, no followup data are available for the patients in our cross-sectional study.

The time given to inform a newly diagnosed patient about RA differs considerably between the 2 countries. Whereas a
Gävle patient commonly attends a 1 -h visit with the rheumatologist to receive an introduction to her/his disease and its treatment during an individual encounter at the doctor's office, the corresponding time in Khartoum is about half as long, and the consultation most often takes place in a common outpatient room with many other consultations going on in parallel.

We have determined that Sudanese patients with RA have more widespread joint involvement and stronger laboratory signs of inflammation compared with Swedish patients with RA. Sudanese patients also have radiological erosions and RA-associated hand deformities to a large extent, although only half of the patients are IgM-RF seropositive. This finding of highly active and often seronegative RA in east-central Africa differs from the rather widespread belief that RA in Africa has a mild clinical course. The Sudanese use of lower MTX doses and higher PSL doses, more patients receiving DMARD combinations, and many patients treated with NSAID only might be owing to structural dissimilarities between healthcare systems, economic prerequisites, and possibilities for extensive patient education and clinical followup of patients with RA in Sudan and Sweden.

\section{REFERENCES}

1. Usenbo A, Kramer V, Young T, Musekiwa A. Prevalence of arthritis in Africa: a systematic review and meta-analysis. PLoS One 2015;10:e0133858

2. Malemba JJ, Mbuyi-Muamba JM, Mukaya J, Bossuyt X, Verschueren P, Westhovens R. The epidemiology of rheumatoid arthritis in Kinshasa, Democratic Republic of Congo-a population-based study. Rheumatology 2012;51:1644-7.

3. Singwe-Ngandeu M, Finckh A, Bas S, Tiercy JM, Gabay C. Diagnostic value of anti-cyclic citrullinated peptides and association with HLA-DRB1 shared epitope alleles in African rheumatoid arthritis patients. Arthritis Res Ther 2010;12:R36.

4. Kalla AA, Tikly M. Rheumatoid arthritis in the developing world. Best Pract Res Clin Rheumatol 2003;17:863-75.

5. McGill PE, Oyoo GO. Rheumatic disorders in Sub-saharan Africa. East Afr Med J 2002;79:214-6.

6. Mody GM, Meyers OL. Rheumatoid arthritis in blacks in South Africa. Ann Rheum Dis 1989;48:69-72.

7. Brighton SW, de la Harpe AL, van Staden DJ, Badenhorst JH, Myers OL. The prevalence of rheumatoid arthritis in a rural African population. J Rheumatol 1988;15:405-8.

8. Chikanza IC, Stein M, Lutalo S, Gibson T. The clinical, serologic and radiologic features of rheumatoid arthritis in ethnic black Zimbabwean and British Caucasian patients. J Rheumatol 1994;21:2011-5.

9. Adebajo AO, Reid DM. The pattern of rheumatoid arthritis in West Africa and comparison with a cohort of British patients. Q J Med 1991;80:633-40.

10. Hodkinson B, Tikly M, Adebajo A. Rheumatoid arthritis in the developing world: stepping up to the challenge. Clin Rheumatol 2014;33:1195-6.

11. McGill P. Rheumatoid arthritis in sub-Saharan Africa. Ann Rheum Dis 1991;50:965-6.

12. Greenwood BM. Polyarthritis in Western Nigeria. I. Rheumatoid arthritis. Ann Rheum Dis 1969;28:488-96.

13. Bagg LR, Hansen DP, Lewis C, Houba V. Rheumatoid arthritis in Kenya. I. Clinical observations. Ann Rheum Dis 1979;38:23-5.

Personal non-commercial use only. The Journal of Rheumatology Copyright $\subset$ 2016. All rights reserved. 
14. Kanyerezi BR, Lutalo SK. Some aspects of rheumatoid disease in Uganda. East Afr Med J 1980;57:39-43.

15. Adelowo OO, Ojo O, Oduenyi I, Okwara CC. Rheumatoid arthritis among Nigerians: the first 200 patients from a rheumatology clinic. Clin Rheumatol 2010;29:593-7.

16. Muller AS, Valkenburg HA, Greenwood BM. Rheumatoid arthritis in three west African populations. East Afr Med J 1972;49:75-83.

17. Mody GM. Rheumatoid arthritis and connective tissue disorders: sub-Saharan Africa. Baillieres Clin Rheumatol 1995;9:31-44.

18. Abdelsalam SK, Hashim NT, Elsalamabi EM, Gismalla BG. Periodontal status of rheumatoid arthritis patients in khartoum state. BMC Res Notes 2011;4:460.

19. Ovretveit J, Keller C, Hvitfeldt Forsberg H, Essen A, Lindblad S, Brommels M. Continuous innovation: developing and using a clinical database with new technology for patient-centred care-the case of the Swedish quality register for arthritis. Int J Qual Health Care 2013;25:118-24.

20. Arnett FC, Edworthy SM, Bloch DA, McShane DJ, Fries JF, Cooper NS, et al. The American Rheumatism Association 1987 revised criteria for the classification of rheumatoid arthritis. Arthritis Rheum 1988;31:315-24.

21. Prevoo ML, van 't Hof MA, Kuper HH, van Leeuwen MA, van de Putte LB, van Riel PL. Modified disease activity scores that include twenty-eight-joint counts. Development and validation in a prospective longitudinal study of patients with rheumatoid arthritis. Arthritis Rheum 1995;38:44-8.

22. Ramos-Remus C, Sierra-Jimenez G, Skeith K, Aceves-Avila FJ, Russell AS, Offer R, et al. Latitude gradient influences the age of onset in rheumatoid arthritis patients. Clin Rheumatol 2007;26:1725-8.

23. Statistics UN. World population prospects: life expectancy. [Internet. Accessed June 17, 2016.] Available from: unstats.un.org/unsd/demographic/products/socind

24. Kaiser Family Foundation Usd. Total fertility rate (children born per woman) United Nations 2012. [Internet. Accessed June 17, 2016.] Available from: unstats.un.org/unsd/demographic/products/socind

25. Hazes JM, Dijkmans BA, Vandenbroucke JP, de Vries RR, Cats A. Pregnancy and the risk of developing rheumatoid arthritis. Arthritis Rheum 1990;33:1770-5.

26. Heliövaara M, Aho K, Reunanen A, Knekt P, Aromaa A. Parity and risk of rheumatoid arthritis in Finnish women. Br J Rheumatol 1995;34:625-8.

27. Spector TD, Roman E, Silman AJ. The pill, parity, and rheumatoid arthritis. Arthritis Rheum 1990;33:782-9.

28. Jacobsen S. Young age of onset is associated with increased prevalence of circulating IgM rheumatoid factor and antinuclear antibodies at presentation in women with rheumatoid arthritis. Clin Rheumatol 2004;23:121-2.

29. Neovius M, Simard JF, Askling J; ARTIS Study Group. How large are the productivity losses in contemporary patients with RA, and how soon in relation to diagnosis do they develop? Ann Rheum Dis 2011;70:1010-5.

30. Sokka T, Toloza S, Cutolo M, Kautiainen H, Makinen H, Gogus F, et al; QUEST-RA Group. Women, men, and rheumatoid arthritis: analyses of disease activity, disease characteristics, and treatments in the QUEST-RA study. Arthritis Res Ther 2009;11:R7.

31. Abdel-Nasser AM, Mahmoud MH, El Mansoury TM, Osman AM. Anti-CCP2 is an adjunct to, not a surrogate for, rheumatoid factor in the diagnosis of rheumatoid arthritis: diagnostic utility of anti-CCP2 antibodies in Egyptian patients with rheumatoid arthritis. Scand J Rheumatol 2008;37:329-36.

32. Lekpa FK, Ndongo S, Tiendrebeogo J, Ndao AC, Daher A, Pouye A, et al. Rheumatoid arthritis in Senegal: a comparison between patients coming from rural and urban areas, in an urban tertiary health care center in Senegal. Clin Rheumatol 2012;31:1617-20.
33. Ouédraogo DD, Singbo J, Diallo O, Sawadogo SA, Tieno H, Drabo YJ. Rheumatoid arthritis in Burkina Faso: clinical and serological profiles. Clin Rheumatol 2011;30:1617-21.

34. Kanyerezi BR, Baddeley H, Kisumba D. Rheumatoid arthritis in Ugandan Africans. Ann Rheum Dis 1970;29:617-21.

35. Davis P, Stein M, Ley H, Johnston C. Serological profiles in the connective tissue diseases in Zimbabwean patients. Ann Rheum Dis 1989;48:73-6.

36. Ibn Yacoub Y, Amine B, Laatiris A, Hajjaj-Hassouni N. Rheumatoid factor and antibodies against citrullinated peptides in Moroccan patients with rheumatoid arthritis: association with disease parameters and quality of life. Clin Rheumatol 2012;31:329-34.

37. Houba V, Bagg LR, Hansen DP, Bowry T. Rheumatoid arthritis in Kenya. II. Serological observations. Ann Rheum Dis 1979;38:26-30.

38. Klareskog L, Stolt P, Lundberg K, Källberg H, Bengtsson C, Grunewald J, et al. A new model for an etiology of rheumatoid arthritis: smoking may trigger HLA-DR (shared epitope)-restricted immune reactions to autoantigens modified by citrullination. Arthritis Rheum 2006;54:38-46.

39. Rönnelid J, Wick MC, Lampa J, Lindblad S, Nordmark B, Klareskog L, et al. Longitudinal analysis of citrullinated protein/peptide antibodies (anti-CP) during 5 year follow up in early rheumatoid arthritis: anti-CP status predicts worse disease activity and greater radiological progression. Ann Rheum Dis 2005;64:1744-9.

40. Mikuls TR, Sayles H, Yu F, Levan T, Gould KA, Thiele GM, et al. Associations of cigarette smoking with rheumatoid arthritis in African Americans. Arthritis Rheum 2010;62:3560-8.

41. Idris AM, Ibrahim YE, Warnakulasuriya KA, Cooper DJ, Johnson NW, Nilsen R. Toombak use and cigarette smoking in the Sudan: estimates of prevalence in the Nile state. Prev Med 1998; 27:597-603.

42. Abusharaf RM. Transforming displaced women in Sudan: politics and the body in a squatter settlement. Chicago: University of Chicago Press; 2009.

43. Chatzidionisyou A, Catrina AI. The lung in rheumatoid arthritis, cause or consequence? Curr Opin Rheumatol 2016;28:76-82.

44. Sluis-Cremer GK, Hessel PA, Hnizdo E, Churchill AR. Relationship between silicosis and rheumatoid arthritis. Thorax 1986;41:596-601.

45. Klockars M, Koskela RS, Jarvinen E, Kolari PJ, Rossi A. Silica exposure and rheumatoid arthritis: a follow up study of granite workers 1940-81. Br Med J 1987;294:997-1000.

46. Hart JE, Laden F, Puett RC, Costenbader KH, Karlson EW. Exposure to traffic pollution and increased risk of rheumatoid arthritis. Environ Health Perspect 2009;117:1065-9.

47. Too CL, Muhamad NA, Ilar A, Padyukov L, Alfredsson L, Klareskog L, et al. Occupational exposure to textile dust increases the risk of rheumatoid arthritis: results from a Malaysian population-based case-control study. Ann Rheum Dis 2016; 75:997-1002.

48. Tikly M, Hodkinson B, Dheda K. Biologic therapy for rheumatoid arthritis in developing countries - a place for non-TNF inhibitors as first-line treatment? Rheumatology 2015;54:208-9.

49. O'Dell JR, Haire CE, Erikson N, Drymalski W, Palmer W, Eckhoff PJ, et al. Treatment of rheumatoid arthritis with methotrexate alone, sulfasalazine and hydroxychloroquine, or a combination of all three medications. N Engl J Med 1996;334:1287-91.

50. O’Dell JR, Leff R, Paulsen G, Haire C, Mallek J, Eckhoff PJ, et al. Treatment of rheumatoid arthritis with methotrexate and hydroxychloroquine, methotrexate and sulfasalazine, or a combination of the three medications: results of a two-year, randomized, double-blind, placebo-controlled trial. Arthritis Rheum 2002;46:1164-70. 